\title{
Os rankings na educação superior brasileira: políticas de governo ou de Estado?*
}

\author{
Adolfo Ignacio Calderón*** \\ Heloisa Poltronieri*** \\ Regilson Maciel Borges****
}

\section{Resumo}

0 presente artigo, de cunho teórico, analisa o lugar dos rankings nas políticas de Educação Superior do Estado Brasileiro tendo como parâmetro quatro mandatos presidências, dois mandatos do governo Fernando Henrique Cardoso (1995-2002), marcados pela implantação das reformas neoliberais, e dois mandatos do governo Luiz Inácio Lula da Silva (2003-2010), como alternativa de esquerda democrática para América Latina diante da expansão neoliberal. Defende-se a hipótese de que passados quatro mandatos e o governo de dois presidentes representantes de projetos políticos teoricamente opostos, os rankings, enquanto estratégias de estímulo da concorrência para a melhoria da qualidade da educação superior ganharam consenso e legitimidade técnica no âmbito governamental, deixando de serem políticas de governos específicos para se tornarem política de longo prazo do Estado Brasileiro, acima dos interesses dos grupos políticos que se alternaram no poder.

Palavras-chave: Rankings. Avaliação educacional. Educação superior. Sinaes. Exame Nacional de Cursos.

* Este estudo contou com o apoio da Fundação de Amparo à Pesquisa do Estado de São Paulo (Fapesp) (processo $n^{\circ}$ 2010/17608-3); as ideias expostas foram discutidas durante o V Congresso Internacional de Avaliação Educacional realizado de 4 a 6 novembro de 2010, na cidade de Fortaleza, Ceará.

** Doutor em Ciências Sociais, Pontifícia Universidade Católica de São Paulo (PUC/SP); Pós-Doutorado em Ciências da Educação, Universidade de Coimbra; docente-pesquisador do Programa de Mestrado em Educação, Pontifícia Universidade Católica de Campinas (PUC-Campinas). E-mail: adolfo.ignacio@puc-campinas.edu.br

*** Pedagoga; Mestranda do Programa de Pós- Graduação em Educação, PUC-Campinas. E-mail: helo_poltronieri@hotmail.com

***** Bacharel em Filosofia; Mestrando do Programa de Pós- Graduação em Educação, PUC-Campinas. Email: regilsonborges@gmail.com 


\section{The Rankings in Brazilian Higher Education: policies of government or State? \\ Abstract}

This article, of a theoretical approach, examines how the rankings work in the policies of Higher Education of Brazilian State, taking as a parameter four presidential terms: two mandates of the government Fernando Henrique Cardoso (1995-2002), marked by the implementation of neoliberal reforms, and the other two of the government Luiz Inácio Lula da Silva (2003-2010), an alternative to the democratic left in Latin America in face of the neoliberal expansion. It is supported the hypothesis that after four terms and two different presidents that represent theoretically opposing political projects, the rankings, considered as strategies for stimulating competition to improve the quality of Higher Education gained technical consensus and legitimacy within the government, ceasing to be policies of specific governments to become longterm policies of the Brazilian State, above the interests of political groups that alternated in power.

Keywords: Rankings. Educational Evaluation. Higher Education. SINAES. National Course Examination.

\section{Los rankings en la educación superior brasileña: ¿políticas de gobierno de estado? Resumen}

El presente artículo, de cuño teórico, analiza el lugar de los rankings en las políticas de Educación Superior del Estado brasileño, y tiene como parámetro cuatro mandatos presidenciales, dos de Fernando Henrique Cardoso (19952002), marcados por la implantación de las reformas neoliberales, y dos del gobierno de Luiz Inácio Lula da Silva (2003-2010), considerado como una alternativa de la izquierda democrática para América Latina frente a la expansión neoliberal. Se defiende la hipótesis de que después de cuatro mandatos y el gobierno de dos presidentes, representantes de proyectos teóricamente opuestos, los rankings, en la condición de estrategias de estímulo de la competición para la mejora de la calidad de la educación superior, obtuvieron consenso y legitimidad técnica en el ámbito gubernamental, dejando de ser vistos como políticas de determinados gobiernos para convertirse en una política a largo plazo del Estado brasileño, sin relación con los intereses de los grupos politicos que se alternaron en el poder.

Palabras clave: Rankings. Evaluación Educacional. Educación Superior. SINAES (Sistema Nacional de Evaluación de la Educación Superior Brasileña). Examen Nacional de Cursos. 


\section{Introdução}

A década de noventa, conhecida como a "Década da Avaliação" (DIAS SOBRINHO, 2003), foi um período em que se experimentou a implantação de grandes sistemas de avaliação em larga escala, em nível nacional, tais como o Sistema de Avaliação da Educação Básica (Saeb), em 1993, o Exame Nacional de Cursos (ENC), o chamado "Provão", em 1995, e o Exame Nacional do Ensino Médio (Enem), em 1998.

Foi um período de expansão da ideologia neoliberal nos Estados Nacionais sob pressão das grandes agências multilaterais, impregnando a lógica do mercado na administração pública sob os princípios da chamada Nova Gestão Pública (GARCIA; ADRIÃ0; BORGUI, 2009), possibilitando a emergência do modelo pós-burocrático na administração pública (ABRUCIO, 2005), a construção do Estado Eficiente (BANCO MUNDIAL, 1997), do Estado Avaliador, (AFONSO, 1999), a passagem da administração burocrática à administração gerencial (PEREIRA, 2005).

Foram dois mandatos do governo Fernando Henrique Cardoso (FHC) (19952002), marcados pela implantação das reformas neoliberais no âmbito da economia e da Administração Pública, e dois mandatos do governo Luiz Inácio Lula da Silva (2003-2010), com promessas de redenção da esquerda diante da expansão neoliberal, uma alternativa de esquerda democrática para América Latina.

Com o fim do mandato do governo FHC, o governo Lula, ancorado em intelectuais que defendiam a chamada "avaliação emancipatória", substitui o "Provão" pelo Sistema Nacional de Avaliação da Educação Superior (Sinaes), o mesmo que vinha carregado de virtuosismo, próprio de regimes presidencialistas, com a missão de eliminar os princípios neoliberais do governo anterior: hipervalorização da concorrência entre as instituições educacionais e dos rankings com ampla divulgação na mídia.

Estudos focados sobre a política de avaliação do segundo governo Lula, realizada por pesquisadores, alguns deles participantes diretos da implantação do Sinaes, denunciaram com pesar, que o governo Lula no seu segundo mandato adotou ou reeditou velhas práticas do governo anterior: "ranking e mídia" (BARREYRO; ROTHEN, 2009, p. 1), retomando medidas próprias do paradigma técnico-burocrático (DIASSOBRINHO, 2008).

Com estas denúncias, se coloca em discussão o afastamento do governo Lula do paradigma emancipatório da avaliação educacional, para abraçar uma perspectiva classificatória, concorrencial e legitimadora de valores neoliberais.

Diante desse cenário convém questionar: porque os tão satanizados rankings por parte da comunidade científica brasileira, ao longo dos oito anos do governo FHC, voltaram a ganhar força nas políticas de avaliação da Educação Superior? Considerando que a definição das políticas públicas é um campo de conflito e ten- 
são de interesses: quem ganha e quem perde com a hipervalorização da concorrência? Até que ponto os rankings e a concorrência podem ser indutores da melhoria da qualidade da educação?

0 fim dos propósitos iniciais do Sinaes - considerado por pesquisadores, como uma mudança na concepção de avaliação, distanciando-se do mercado, para focarse no desenvolvimento institucional por meio de um ciclo avaliativo e instrumentos de autoavaliação - representa a consagração da hegemonia dos valores neoliberais na avaliação, e em decorrência, a derrota da avaliação processual, formativa, democrática e emancipatória?

Será que os rankings, considerados como uma política específica do governo $\mathrm{FHC}$, ganharam consenso a ponto de se legitimarem como políticas de longo prazo do Estado Brasileiro, independendo de qual grupo político está no poder, seja de direita, centro ou esquerda?

0 presente artigo analisa o ranking como instrumento de avaliação e indutor de qualidade da educação no Brasil, tomando como referência os governos FHC e Lula. Defende a hipótese de que passados quatro mandatos e o governo de dois presidentes representantes de projetos políticos diferenciados, os rankings enquanto estratégias de estímulo da concorrência para a melhoria da qualidade da educação superior ganharam consenso e legitimidade deixando de serem políticas de Estado, com vigência no mandato de governos específicos, para se tornarem política do Estado Brasileiro com vigência de longo prazo, acima dos interesses dos grupos políticos que se alternam no poder.

Nesta perspectiva, os rankings ganharam primazia e legitimidade técnica enquanto instrumentos de avaliação, incorporando as orientações da Nova Gestão Pública na área da educação: a concorrência como elemento indutor da qualidade, a avaliação por resultados como referência para auferir a qualidade, a transparência das informações como elemento chave para o controle e atuação dos consumidores e a responsabilização das Instituições Educacionais pela melhoria da qualidade e pelo desempenho dos alunos.

\section{As políticas de estado e as políticas de governo}

No âmbito do estudo da Administração da Educação, especificamente no desenho, implantação e avaliação das políticas educacionais, tornou-se comum a utilização de duas categorias de análise, as chamadas as Políticas de Estado e as Políticas de Governo.

Trata-se de duas categorias teóricas que, como afirma Rosa (2003), são de grande utilidade embora apresentem algumas armadilhas que muitas vezes podem gerar confusões semânticas e inconsistências de análise. 
Para desenvolver a presente análise, convém registrar o que se entende por Estado, Governo e Políticas Públicas. Para tanto, toma-se como referência conceitual, os apontamento de Höfling (2001, p. 31), que entende por Estado "o conjunto de instituições permanentes - como órgãos legislativos, tribunais, exército e outras que não formam um bloco monolítico necessariamente - que possibilitam a ação do governo".

\section{Por sua vez entende por Governo}

0 conjunto de programas e projetos que parte da sociedade (políticos, técnicos, organismos da sociedade civil e outros) propõe para a sociedade como um todo, configurando-se a orientação política de um determinado governo que assume e desempenha as funções de Estado por um determinado período (HÖFLING, 2001, p. 31).

Nesta relação Estado-Governo, as políticas públicas são consideradas como o "Estado em Ação", isto é, "o Estado implantando um projeto de governo, através de programas, de ações voltadas para os setores específicos da sociedade" (HÖFLING, 2001, p. 31).

Assim, as Políticas Públicas são ações do Estado, a partir das orientações de um determinado governo, que não são necessariamente políticas estatais, sendo compreendidas

Como as de responsabilidade do Estado - quanto à implementação e manutenção a partir de um processo de tomada de decisões que envolve órgãos públicos e diferentes organismos e agentes da sociedade relacionados à política implementada (HÖFLING, 2001, p. 31).

Partindo deste esclarecimento conceitual, pode-se afirmar que existe uma dicotomia falsamente criada entre as Políticas de Estado e as Políticas de Governo, uma vez que toda Política de Governo é uma Política de Estado e, por sua vez, toda Política de Estado é resultado de uma Política de Governo, isto é, das decisões consensuadas do grupo político que está no poder, na direção do Estado (ROSA, 2003, p. 85).

Embora sendo uma falsa dicotomia, pode-se afirmar que tanto autores sistêmicos (LOBO, 1990) como autores que se enquadram dentro das chamadas teorias críticas (SGUISSARDI; SILVA JUNIOR, 2005; FREITAS, 2007), estes últimos grandes formadores de mestres e doutores e referências no âmbito das Ciências da Educação, utilizam as categorias Políticas de Estado e Políticas de Governo para distinguir as políticas de longo prazo das políticas de curto prazo.

Assim, toda a política relativa à universidade haverá de ser uma política de Estado, e não de governo, tendo por objetivo ordenar as relações que materializam a sociedade na direção da intensificação de seus traços de humanidade (SGUISSARDI; SILVA JUNIOR, 2005, p. 17-18). 
0 que propomos é um modelo alternativo baseado na mobilização da comunidade local da escola, com a finalidade dupla de comprometer-se com resultados e, ao mesmo tempo, demandar do poder público condições para tal. Uma proposta como esta só pode ser implementada como política de Estado. Governos temem demandas [...] Espera-se do governo federal uma política de Estado para o ensino fundamental e para sua avaliação (FREITAS, 2007, p. 980-982).

Nessa dicotomia entre as categorias de análise em questão, as Políticas de Estado estariam em um nível superior numa escala ético-hierarquica em relação às Políticas de Governo, na medida em que estariam direcionadas a atender necessidades nacionais acima de discussão e de interesses dos diversos grupos de poder que interagem na sociedade.

Nessa relação hierárquica, a categoria Políticas de Estado é utilizada para defender políticas públicas ou orientações estatais que possuem razões éticas que impedem que sejam substituídas ou alteradas com as mudanças de governo.

Desta forma, as políticas de Estado não somente seriam políticas de longo prazo, mas seriam medidas que não poderiam ser substituidas ou alteradas com as mudanças de governo, a cada quatro anos ou a cada oito anos, caso o governo seja reeleito.

Contudo, a defesa de Políticas de Estado não diz respeito somente a intelectuais que se ancoram nas chamadas teorias críticas, que no âmbito da avaliação educacional giram em torno da chamada "avaliação emancipatória". Trata-se de um recurso teórico utilizado pelos diferentes grupos intelectuais para a defesa categórica de ideias e valores que devem sustentar as políticas públicas. Dai a existência de teóricos que também defendem, como política de Estado, a não intervenção estatal no âmbito do mercado educacional (CASTRO, 2010).

Apesar de serem, semanticamente falando, categorias sustentadas numa falsa dicotomia, as Políticas de Estado como políticas a longo prazo, isenta das mudanças decorrente da alternância do poder, ganham um componente utópico, no sentido negativo, de lugar nenhum, a partir da sua extrema dificuldade de concretização dentro do regime presidencialista.

Convém mencionar que esse regime se sustenta em estruturas políticas pautadas pela hipercentralização do poder na figura do presidente e os processos eleitorais se baseiam em jogos de "soma zero", nos quais um grupo político leva tudo e os outros não levam nada, ficando na oposição até o próximo pleito eleitoral.

Esta afirmação sobre o componente utópico das categorias analíticas em questão, ganha maior sustentação quando constatamos, a partir dos trabalhos de Lech- 
ner (1996), que levar a cabo uma "Política de Estado" - baseada em acordos de longo prazo que evitem a soma zero entre governo e oposição - exige um projeto de país, baseado no consenso nacional, em torno de uma referência norteadora de longo prazo, que facilite um processo de desenvolvimento em que todos os atores possam remar harmonicamente numa mesma direção.

Como viabilizar um projeto de país baseado em acordos de longo prazo em regimes presidencialistas em que prima a "soma zero" nos pleitos eleitorais? Como atingir um consenso nacional que seja respeitado pelos sucessivos governos? Pelo princípio da maioria? 0 principio da maioria é da maioria, não é de todos. Pela ilusão do princípio do Bem Comum? Será que a minoria vai aceitar passivamente, a longo prazo, que seus interesses sejam excluídos da agenda pública?

Como já afirmou Schumpeter (1984), não existe um bem comum determinado em torno do qual todas as pessoas e grupos sociais concordem. Não existe uma vontade do povo única. Não existe um governo do povo. 0 papel do povo é produzir um governo que representa interesses de grupos e setores da sociedade.

As orientações adotadas pelos governos podem ganhar consenso e hegemonia num determinado contexto ou cenário, mas nada garante sua permanência a longo prazo, nem mesmo a sua consagração na Constituição Federal (BRASIL, 1988), uma vez que a partir das próprias regras do jogo podem surgir ou ressurgir ideias e propostas hegemônicas. São vários os exemplos emblemáticos sobre a mudança de curso de "Políticas de Estado": dentre elas, podemos registrar importantes metas apresentadas na Lei $n^{\circ} 10.172$ (BRASIL, 2001), que estabeleceu o Plano Nacional de Educação, as mesmas que não foram cumpridas, ficando relegadas a segundo plano de acordo com os governos que se alternaram no poder.

Sob esta ótica, fica claro que as políticas dos diversos governos que vão se alternando no controle do Estado são em sua essência políticas de Estado, as quais vão ganhando novos contornos diante das novas disputas de poder e dos conflitos entre os diversos grupos de interesses que interagem no sistema. As Políticas do Estado vão se redefinindo de forma contínua e permanente a partir dos diversos inputs de demanda.

A Política de Estado vai sendo construída e moldada, dentro das regras do jogo, no respeito da lei, a partir do controle do Estado por diversos grupos políticos, existindo muitas vezes comuns denominadores entre as Políticas dos Governos a partir de consensos que passam a se constituir a base da atuação governamental, como é o caso da adoção de rankings como indutores de qualidade e seu sequenciamento como modelo de avaliação.

As rupturas são resultados do próprio sistema presidencialista, da falta de consenso. A permanência é resultado do consenso e da hegemonia em torno da validade e legitimidade de determinadas políticas públicas e estratégias de ges- 
tão. A Política de Estado é isso: rupturas, continuidades, consensos, dissensos, hegemonia de valores e princípios dos diversos grupos que estão no poder. A respeito da viabilidade de uma política consensual, a longo prazo, imune a rupturas e descontinuidades, pesquisas apontam que é possível em sistemas parlamentaristas, a partir dos incentivos à cooperação, fato que precisaria outro espaço para maior aprofundamento (STEFAN, 1990).

\section{Os rankings como política do estado brasileiro}

Os rankings, prática que teve início no mundo empresarial norte-americano (DIAS SOBRINHO, 2008), surgem no cenário educacional brasileiro em 1996, com a divulgação dos primeiros resultados do recém criado Exame Nacional de Cursos, o "Provão".

Implementado no Governo FHC, o exame contava com dois instrumentos, um teste de conhecimentos específicos (múltipla escolha e também discursivo) e um questionário, e era aplicado aos alunos concluintes dos cursos de graduação. Foi posteriormente complementado com a Avaliação das Condições de Ensino (ACE) e a Avaliação Institucional.

Durante seus oito anos de duração (1996-2003), o "Provão" recebeu inúmeras críticas da comunidade acadêmica, dentre as quais se destacam a utilização dos resultados do desempenho dos alunos para conceituar as instituições e a apresentação dos resultados em forma de rankings (POLIDORI, 2009).

Para alguns autores críticos do exame (BARREYRO; ROTHEN, 2004; BRITO, 2008; DIAS SOBRINHO, 2010), os rankings construídos a partir dos resultados da prova serviam muito mais para fins de marketing e propaganda do que para compreender os processos envolvidos, tendo em vista que:

[...] uma boa situação no ranking produz uma imagem favorável no mercado, aumenta a atratividade e os benefícios econômicos. Como o Provão não se preocupou em avaliar a complexidade do fenômeno educativo, nem mesmo a complexidade da aprendizagem, para as IES privadas tornou-se cômodo e conveniente moldar um currículo e um estilo de ensino que produzissem melhores resultados estudantis no exame nacional (DIAS SOBRINHO, 2010, p. 207).

Além disso, no entendimento de Barreyro e Rothen (2004, p. 7), o "Provão" funcionou como referencial para dupla regulação, estatal e de mercado:

A avaliação deixou de ser um processo político instaurado no âmago das Instituições de Educação Superior e passou a ser de responsabilidade das agências governamentais. A avaliação deixou de ter uma ferramenta de gestão e de autoconhe- 
cimento das instituições e passou a ser uma ferramenta de controle e principalmente de informação ao mercado sobre a qualidade do produto educação oferecido pelas instituições.

Apesar das duras críticas que recebeu o "Provão", autores que podemos enquadrar nas chamadas teorias críticas (POLIDORI, 2009; DIAS SOBRINHO, 2010) concordam que ele foi um marco na Educação Superior Brasileira, pois colocou a avaliação na agenda educacional e da própria sociedade.

Diante dessas críticas, alguns defensores do Exame (DURHAM, 2003; ARAÚJO FILHO, 2003; CASTRO, 2003) argumentavam que a comparação entre as universidades era uma boa estratégia para a identificação dos pontos fracos que deviam ser melhorados, bem como promoveria uma competição saudável entre as diferentes instituições em busca de qualidade.

Além disso, acreditavam que a divulgação dos resultados avaliativos do "Provão" estaria atrelada a ideia de transparência de informação à sociedade quanto ao nível qualitativo dos cursos, interessando, sobretudo, aqueles que pretendiam ingressar no Ensino Superior (ARAÚJO FILHO, 2003; CASTRO, 2003):

Os cidadãos, antes de definirem suas escolhas, dispõem de referências e parâmetros em relação a cursos similares de instituições diferentes. Na outra ponta, o mercado de trabalho dispõe de dados efetivos para avaliar a formação dos candidatos às suas vagas (CASTRO, 2003, p. 1).

Passado oito anos de execução do ENC, em 2004, no então Governo Luiz Inácio Lula da Silva, é criado o Sistema Nacional de Avaliação da Educação Superior (Sinaes), que inclui: o Exame Nacional do Desempenho dos Estudantes (Enade), a Avaliação das Instituições de Ensino Superior (Avalies) e a Avaliação dos Cursos de Graduação (ACG).

O Sinaes surgiu como uma nova proposta para a avaliação da Educação Superior, buscando superar a ênfase de mercado dada pelo governo anterior. Sua proposta principal era a implantação de um sistema avaliativo emancipatório indo além da visão neoliberal. Partia de uma concepção global de avaliação (DIAS SOBRINHO, 2010).

Dos três instrumentos de avaliação, o Enade adquiriu grande destaque no Ministério da Educação e na mídia, emergindo novamente os rankings, apontados por Dias Sobrinho (2010) e Brito (2008), como uma atitude equivocada da mídia. Assim, diferentemente do que propunham os seus formuladores, o Enade acabou sendo tomado como principal fonte de informação para a formulação dos índices de qualidade.

Com a criação do Conceito Preliminar de Cursos (CPC) e o Índice Geral de Cursos (IGC), em 2008, contrariando a expectativa de que o SINAES teria um papel 
central na regulação (BARREYRO; ROTHEN, 2009), o próprio Ministério da Educação começa a divulgar os rankings, algo que até então não havia ocorrido, pois no governo anterior quem elaborava o ranking era a imprensa.

Polidori (2009) considera a elaboração e divulgação de rankings pelo próprio Ministério da Educação um novo fenômeno no qual se hierarquizam os melhores e os piores cursos de nível superior do país, utilizando-se somente uma avaliação realizada pelos estudantes.

Assim, assiste-se a um fenômeno semelhante que ocorreu na era FHC: a sobreposição e a primazia de um instrumento de avaliação sobre os demais. Naquele governo, o "Provão" ganhava a mídia e ficavam no ostracismo os outros instrumentos: Avaliação das Condições de Ensino (ACE) e a Avaliação Institucional. 0 fenômeno se repete no segundo mandato do governo Lula. 0 Enade ganha a mídia, enquanto a Avaliação Institucional e, principalmente, a Autoavaliação ficaram no ostracismo.

Desta forma, o Provão e o Enade, que têm na sua essência a elaboração de rankings se constituem nos instrumentos indutores da qualidade por meio da concorrência, dinamizando o mercado educacional.

Para Brito (2008, p. 850):

Se o objetivo fundamental do ENADE vai ser produzir um ranqueamento, os ingressantes devem ser excluídos do exame porque apenas prejudicam os resultados das IES. 0 objetivo central do exame foi perdido porque ele foi feito para aferir o progresso do estudante e o questionário da avaliação discente pode ser resumido a duas questões. 0 ENADE evoluiu ou regrediu? Do meu ponto de vista regrediu.

A regressão a que se refere Brito (2008) é ratificada por Barreyro e Rothen (2009) que defendem a hipótese de que a adoção dos Índices no segundo mandato do governo Lula permitiria a reedição de velhas práticas e os autores questionam: seria para o governo Lula um constrangimento assumir que o antigo Ministro da Educação, Paulo Renato Souza, estava certo ao defender o Provão/Enade como "o instrumento por excelência para a regulação da Educação Superior?"

No primeiro Governo Lula, de forma conturbada, criou-se um sistema que vinculava a regulação da educação superior a um sistema de avaliação, o Sinaes. No segundo Governo, adotando-se a visão economicista de criar índices, foi reeditada a prática do ranqueamento, desenvolvida pela imprensa durante os governos $\mathrm{FHC}$, estimulando o uso mercantil dos resultados e promovendo a concorrência entre instituições" (BARREYRO; ROTHEN, 2009, p. 13). 
Os autores ancoram essa análise sobre a supervalorização do Enade ao citar as reflexões do presidente da Comissão Especial que propôs a criação do Sinaes, José Dias Sobrinho (apud BARREYRO; ROTHEN, 2009, p. 10), que afirmou:

0 Inep destituiu a avaliação institucional e erigiu o ENADE agora um exame estático e somativo, não mais dinâmico e formativo - como centro de sua avaliação, atribuindo-lhe um peso muito maior do que ele tinha antes. Isso não é uma simples mudança de metodologia. É sim, uma mudança radical do paradigma de avaliação: da produção de significados e reflexão sobre os valores do conhecimento e da formação, para o controle, a seleção, a classificação em escalas numéricas.

Para os autores em questão, o passo seguinte "no resgate da herança $\mathrm{FHC}$ " no sentido de transformar o "Enade" no elemento fundamental da avaliação de cursos - foi a edição da Portaria Normativa nº 40 (BRASIL, 2007), que anunciava a criação do Conceito Preliminar de Cursos.

De acordo com essa Portaria, a renovação de reconhecimento de cursos teria como parâmetro a atribuição de um conceito preliminar, gerado a partir dos dados do Censo da Educação Superior, dos resultados do Enade e de cadastros do MEC. Caso esse conceito preliminar fosse satisfatório, poderia ser dispensada a realização da avaliação in loco (BARREYRO; ROTHEN, 2009, p. 10).

\section{Conclusão}

Em artigo publicado em 2007, Luiz Carlos de Freitas afirmou:

A surpresa, em matéria de avaliação do ensino fundamental, neste momento, fica por conta do aprofundamento das políticas liberais da era FHC sob o governo de Luiz Inácio Lula da Silva [...]. Ao passo que a política de avaliação do ensino superior, com a eliminação do Provão e a constituição do SINAES, parece caminhar no rumo certo, a política de avaliação do Ensino Fundamental envereda por caminhos duvidosos (FREITAS, 2007, p. 966).

As pesquisas de Barreyro e Rothen (2009) e de Dias Sobrinho (2008), atualizam os dados de Freitas (2007) na medida em que constatam que as políticas neoliberais do governo de $\mathrm{FHC}$ foram aprofundadas pelo governo Lula não somente no âmbito da avaliação da Educação Básica mas também da Educação Superior.

As mudanças nas orientações da Política do Estado na área da Educação Superior são resultados da alternância de governo e das múltiplas pressões que sofrem os 
governos, sejam no âmbito da intelectualidade, dos empresários, dos consumidores, das agências multilaterais, dos grupos de sustentação política, entre outros.

Passados quatro mandatos e dois governos, apesar de satanizados pela grande maioria pela intelectualidade, os rankings emergem como uma ave fênix que ressurge das cinzas.

Com a retomada dos rankings como indutor da qualidade, por meio do estímulo da concorrência, bem como com a tentativa da retomada da criação de uma cultura do ranqueamento e de transparência de informações para o cliente consumidor, que atualmente beira a $70 \%$ do total das matriculas no Ensino Superior, criam-se as condições para o fortalecimento do mercado educacional, na medida em que o consumidor poderá ter elementos referências sobre os diversos cursos ofertados, seja por universidades públicas ou privadas, fato que auxiliará no momento da escolha.

Assim, o Brasil se adequa às tendências do mundo globalizado, como é o caso da União Européia, por meio da implantação da Declaração de Bolonha, cenário no qual, como afirmam Lima, Azevedo e Catani (2008), está em curso a implantação de um mercado competitivo de Educação Superior, por meio da criação de regras de competição e de critérios de avaliação da sua qualidade, visando a prestar informações aos "consumidores".

\section{Referências}

ABRUCIO, F. Os avanços e os dilemas do modelo pós-burocrático: a reforma da administração pública à luz da experiência internacional recente. In: PEREIRA, L. C. B.; SPINK, P. (Org.). Reforma do Estado e administração pública gerencial. Rio de Janeiro: Ed. FGV, 2005. p. 173-99.

AFONSO, A. J. Estado, mercado, comunidade e avaliação: esboço para uma rearticulação crítica. Educação \&t Sociedade, Campinas, SP, ano 20, n. 69, p. 139-164, 1999.

ARAÚJO FILHO, M. S. Acabar com o Provão: um retrocesso (anunciado) para o ensino superior brasileiro. Jornal da Ciência, São Paulo, 7 maio 2003. Disponível em: <http://www.jornaldaciencia.org.br/Detalhe.jsp?id=9597>. Acesso em: 26 set. 2010.

BANCO MUNDIAL. O Estado em um mundo em transformação. Washington, 1997.

BARREYRO, G. B.; ROTHEN, J. C. Avaliação da educação superior no segundo governo Lula: "Provão II" ou a reedição de velhas práticas?. In: REUNIÃO ANUAL DA ASSOCIAÇÃO NACIONAL DE PÓS-GRADUAÇÃO E PESOUISA EM EDUCAÇÃO 32., 2009, Caxambu. Anais... Rio de Janeiro: Anped, 2009. p.1-18. 
BARREYRO, G. B.; ROTHEN, J. C. Do Provão ao Sinaes: o processo de construção de um novo modelo de avaliação da educação superior. Avaliação, Campinas, v. 9, n. 2, p. 37-49, 2004.

BRASIL. Constituição (1988). Constituição da República Federativa do Brasil de 1988. Brasilia, DF, 1988. Disponivel em: <http://www.planalto.gov.br/ccivil_03/ constituicao/constitui\%C3\%A7ao.htm >. Acesso em: 25 out. 2011.

Lei ${ }^{0}$. 10.172, de 9 de janeiro de 2001. Aprova o Plano Nacional de Educação e dá outras providências. Diário Oficial da União, Brasília, DF, 10 jan. 2001.

Ministério da Educação. Portaria Normativa no. 40, de 12 de dezembro de 2007. Diário Oficial da União, Brasília, DF, n. 239, 13 dez. 2007. Seção 1, p. 39-43.

BRITO, M. R. F. O Sinaes e o Enade: da concepção à implementação. Avaliação, Campinas, v. 13, n. 3, p. 841-850, 2008.

CASTRO, C. M. A educação no próximo governo. Digesto Econômico, São Paulo, ano 65, n. 456, p. 6-23, mar. 2010.

CASTRO, M. H. G. Quem tem medo do Provão? Jornal da Ciência, São Paulo, 29 set. 2003. Disponivel em: <http://www.jornaldaciencia.org.br/

Detalhe.jsp?id=13126>. Acesso em: 26 set. 2010.

DIAS SOBRINHO, J. Avaliação: políticas educacionais e reformas da educação superior. São Paulo: Cortez, 2003.

Avaliação e transformações da educação superior brasileira (1995-2009): do Provão ao Sinaes. Avaliação, Campinas, v. 15, n. 1, p. 195-224, 2010.

. Qualidade, avaliação: do Sinaes a Índices. Avaliação, Campinas, v. 13, n. 3, p. 817-825, 2008.

DURHAM, E. O Provão deve ser extinto? Não. Jornal da Ciência, São Paulo, 8 set. 2003. Disponivel em: <http://www.jornaldaciencia.org.br/Detalhe.jsp?id=12577>. Acesso em: 25 set. 2010.

FREITAS, L. C. Eliminação adiada: o ocaso das classes populares no interior da escola e a ocultação da (má) qualidade do ensino. Educação e Sociedade, Campinas, v. 28, n. 100, p. 965-987, 2007. 
GARCIA, T.; ADRIÃO, T.; BORGHI, R. A nova gestão pública e o contexto brasileiro. In: MARTINS, A. M. (Org.). Instituições educacionais: políticas, gestão e práticas profissionais. Santos: Ed. Universitária Leopoldianum, 2009.

LECHNER, N. Reforma do Estado e condução política. Lua Nova: revista de cultura e política, São Paulo, n. 37, p. 33-56, 1996.

LIMA, L. C.; AZEVEDO, M. L. N.; CATANI, A. M. 0 processo de Bolonha, a avaliação da educação superior e algumas considerações sobre a Universidade Nova. Avaliação, Campinas, v. 13, n. 1, p. 7-8, 2008.

LOBO, T. Descentralização: conceitos, princípios e prática governamental. Revista de Estudos e Pesquisa em Educação, São Paulo, n. 74, p. 5-10, ago. 1990.

PEREIRA, L. C. B. Gestão do setor público: estratégia e estrutura para um novo Estado. In: PEREIRA, L. C. B.; SPINK, P. (Org.). Reforma do Estado e administração pública gerencial. Rio de Janeiro: Ed. FGV, 2005. p. 21-38.

POLIDORI, M. M. Políticas de avaliação da Educação Superior brasileira: Provão, Sinaes, IDD, CPC, IGC e... outros Índices. Avaliação, Campinas, v. 14, n. 2, p. 439452, 2009.

ROSA, S. Reforma da previdência: política de Estado ou política de governo? Res Pvblica, Brasília, DF, n. 2, p. 80-98, 2003.

SCHUMPETER, J. Capitalismo, socialismo e democracia. Rio de Janeiro: Zahar, 1984.

SGUISSARDI, V.; SILVA JÚNIOR, J. dos R. As novas faces da educação superior no Brasil: reforma do Estado e mudança na produção. São Paulo: Cortez, 2001.

STEFAN, A. Parlamentarismo $X$ presidencialismo no mundo moderno: revisão de um debate atual. Estudos Avançados, São Paulo, v. 4, n. 8, p. 96-107, 1990.

Recebido em: 10/12/2010

Aceito para publicação em: 04/09/2011 